\title{
Chromosome distribution studies in XXY karyotypes
}

\author{
M KIRSCH-VOLDERS, L HENS, H VAN DEN BERGHE, B SCHOLBERG, \\ AND C SUSANNE \\ From the Laboratorium voor Antropogenetika, Vrije Universiteit Brussel, Pleinlaan 2 F4, \\ 1050 Brussels, Belgium
}

SUMMARY The method of 'generalised distances' was applied to characterise the relative position of the metaphase chromosomes in a population of XXY subjects (189 metaphases from 28 subjects).

The most striking observation was that the presence of an extra gonosome coincided with a disturbance of the normally stable centromere-centre distribution pattern. The distribution analysis gave no clear cut evidence for the induction of gonosomal trisomy XXY by chromosome association. No significant association was observed between $X$ and $X$ or $X$ and $Y$ but there was a smaller distance between $\mathrm{X}$ and $\mathrm{Y}$ in $\mathrm{XXY}$ karyotypes than in $\mathrm{XY}$ karyotypes.

As far as autosomes are concerned, the XXY karyotypes were characterised by a less central location of the acrocentrics without a clear decrease of association frequencies of these acrocentrics, and the $\mathrm{C}$ heterochromatin rich chromosomes were more often associated than in the $\mathrm{XX}$ and $\mathrm{XY}$ control populations.

These data do not support the idea that gonosomal trisomies result from chromosome associations, but favour the hypothesis that spindle degeneration as a result of intrafollicular ageing or $\mathrm{C}$ heterochromatin polymorphism may be responsible for non-disjunctions.

Different mechanisms have been considered to be responsible for non-disjunctions in trisomies. Nondisjunction may be induced by spindle degeneration as a result of intrafollicular ageing. ${ }^{1}$ Close associations between chromosomes, on the other hand, were shown to induce trisomy 21 , for example. ${ }^{2}$ These associations are governed by the presence of rDNA connectives $^{3}$ in combination with RRNA $^{4}$ and proteins and by the existence of repetitive DNA families, for example in the $\mathrm{C}$ heterochromatin blocks of chromosomes $1,9,16$, and $\mathrm{Y}^{5}$

An analysis of the relative position of chromosomes in cells from trisomic patients and their parents would at least help to clarify the role of chromosome associations in the induction of trisomies. The determination of the centromere to centromere distances would show whether the chromosomes involved in the trisomy lie closer to each other or to some specific chromosome pair. The analysis of the centromere-centre distances would define whether the presence of an extra chromosome modifies the generally stable organisation of chromosomes as to the metaphase plate centre. ${ }^{5}$

We applied the objective method of 'generalised distances $^{3-8}$ to characterise the relative position of the metaphase chromosomes in a population of XXY subjects (189 metaphases from 28 subjects).

\section{Material and methods}

Peripheral blood samples were taken from $28 \mathrm{XXY}$ patients (mean age $=24 \cdot 2$, range $=0-61$ ). The peripheral lymphocytes were cultured for 72 hours, fixed, and spread on slides. ${ }^{9}$ The metaphases were $\mathrm{G}$ banded and karyotyped (one subject, 12 metaphases; one, 11 metaphases; one, ten metaphases; one, nine metaphases; one, eight metaphases; eight, seven metaphases; eight, six metaphases; and seven, five metaphases).

The control groups consisted of two previously analysed populations ${ }^{5}{ }^{8}: 100$ metaphases from ten normal 20-year-old human males (ten metaphases per person) and 50 metaphases from ten normal 20-year-old human females (five metaphases per person).

Numerical information on the relative position of the chromosomes in metaphases was obtained as previously described. 5 ; 810

Briefly, the co-ordinates of all chromosomes in each metaphase plate were recorded and a circular 
transformation was then performed according to Barton et $a l^{11}$ to obtain the 'generalised square distance $\Delta^{2}$, (between the centromere of two chromosomes), the 'generalised square distance $\mathrm{d}^{2}$, (between the centromere of a chromosome and the centre of gravity of the metaphase), and the 'generalised angle value' (smallest angle formed between a centromere, the centre of gravity, and another centromere). These values allow a direct comparison between the different metaphases independently of their form and photographic magnification.

Within the investigated populations, $\mathrm{d}^{2}$ values (or $\triangle^{2}$ angle values) for a given chromosome combination were ranked in histogram classes with equal intervals. When all $\mathrm{d}^{2}$ values (or $\triangle^{2}$ or angle values) from all metaphases of a particular population are compiled on one histogram, the distribution provides a reference histogram for this population.

The statistical significance of distributions obtained in the different populations were analysed by $\chi^{2}$ tests based on calculations with the above mentioned absolute class frequencies. Graphically, however, these classes were compared as percentage frequencies. Three different types of $\chi^{2}$ comparisons were performed.

(1) $\chi^{2}$ tests within the control populations and within the $X X Y$ population

The distribution of the $\mathrm{d}^{2}, \triangle^{2}$, or angle values of each chromosome combination in a given population was compared with the reference distribution of its own population. In order to obtain independence between the reference distribution and the distribution for a particular chromosome combination, the absolute class frequencies of the distribution of that particular chromosome combination were subtracted from the absolute class frequencies of the reference distribution. Then, by $\chi^{2}$ tests, it is possible to decide whether the $\mathrm{d}^{2}, \Delta^{2}$, or angle distribution of a given chromosome combination differs significantly from the reference distribution.

(2) $\chi^{2}$ tests between the control populations and the $X X Y$ populations

(a) The distribution of the $\mathrm{d}^{2}$ or $\triangle^{2}$ values of each chromosome combination in the XXY population was compared with the corresponding combination in the $X X$ and $X Y$ control populations. This type of $\chi^{2}$ test allows us to decide for the two groups investigated whether the compared distribution belongs to the same population of numbers. (b) The first class of the distribution of the $\stackrel{\infty}{\mathbb{\Phi}}$ chromosome combination in the XXY population was compared with the first class of the distribution of the corresponding chromosome $\overrightarrow{0}$ combination in the $\mathrm{XX}$ and $\mathrm{XY}$ control $\frac{}{\sigma}$ populations. $\chi^{2}$ tests were then performed by considering only two classes: the absolute $\vec{\nabla}$ frequencies corresponding to the first class of the distribution (lowest $\Delta^{2}$ values) and the ${ }^{2}$ pooled frequencies of the remaining classes. Thus $\vec{\circ}$ we have only one degree of freedom in this $\overrightarrow{\vec{\omega}}$ analysis. This type of test has already been $\stackrel{\omega}{\sigma}$ defined by us $^{7}$ as a measure of the association tendency between two chromosomes.

The data were processed on a CDC 6400 computer in the Université Libre de Bruxelles-Vrije vi Universiteit Brussel mathematical centre.

\section{Results}

DistanCE TO THE METAPHASE PLATE CENTRE ( $\mathrm{d}^{2}$ VALUES)

$\chi^{2}$ test within the control populations and within the $X X Y$ population

Table 1 gives for each homologous chromosome pair in the different populations studied the mean $\mathrm{d}^{2}$

TABLE $1 \bar{d}^{2}$ values and rank $(r)$ values for the control and the patient populations

\begin{tabular}{|c|c|c|c|c|c|c|}
\hline \multirow[b]{2}{*}{ Chromosome } & \multicolumn{2}{|l|}{$X Y$} & \multicolumn{2}{|l|}{$X X$} & \multicolumn{2}{|l|}{$X X Y$} \\
\hline & $\bar{d}^{2}$ & $r$ & $\bar{d}^{2}$ & $r$ & $\bar{d}^{2}$ & $r$ \\
\hline 1 & $1 \cdot 871$ & 8 & $1 \cdot 925$ & 10 & $1 \cdot 745^{*}$ & 1 \\
\hline 2 & $2 \cdot 168$ & 17 & $2 \cdot 229$ & 21 & $1 \cdot 931$ & 7 \\
\hline 3 & $2 \cdot 169$ & 18 & $2 \cdot 222$ & 19 & 1.983 & 11 \\
\hline 4 & $2 \cdot 264 \ddagger$ & 21 & $2 \cdot 166$ & 18 & $2 \cdot 040$ & 15 \\
\hline 5 & $2 \cdot 410 \ddagger$ & 23 & $2 \cdot 102$ & 15 & $1 \cdot 961$ & 10 \\
\hline 6 & $2 \cdot 254 t$ & 20 & $2 \cdot 412^{*}$ & 22 & $2 \cdot 124$ & 22 \\
\hline 7 & $2 \cdot 107$ & 15 & $1 \cdot 868$ & 8 & 2.006 & 13 \\
\hline 8 & 2.055 & 13 & 2.068 & 13 & 2.071 & 16 \\
\hline 9 & $2 \cdot 277$ & 22 & 2.069 & 14 & 2.013 & 14 \\
\hline 10 & $2 \cdot 155$ & 16 & $2 \cdot 105$ & 16 & 2.073 & 17 \\
\hline 11 & $2 \cdot 233$ & 19 & 1.952 & 11 & $2 \cdot 215$ & 24 \\
\hline 12 & 2.094 & 14 & $2 \cdot 228$ & 20 & 1.942 & 9 \\
\hline 13 & $1.625 t$ & 3 & $1 \cdot 821$ & 6 & 1.929 & 6 \\
\hline 14 & 1.892 & 10 & $1 \cdot 760$ & 2 & 1.904 & 4 \\
\hline 15 & $1 \cdot 757 \ddagger$ & 5 & $1 \cdot 718$ & 1 & $1 \cdot 866$ & 3 \\
\hline 16 & $1 \cdot 805$ & 6 & 2.069 & 14 & 1.931 & 7 \\
\hline 17 & 1.917 & 11 & 1.906 & 9 & $2 \cdot 116^{*}$ & 20 \\
\hline 18 & 1.819 & 7 & $1 \cdot 816$ & 5 & $2 \cdot 126$ & 23 \\
\hline 19 & 1.753 & 4 & 1.972 & 12 & 2.003 & 12 \\
\hline 20 & $1 \cdot 877$ & 9 & $1 \cdot 790$ & 4 & $2 \cdot 110$ & 19 \\
\hline 21 & $1 \cdot 486^{*}$ & 1 & $1 \cdot 787$ & 3 & 1.909 & 5 \\
\hline 22 & $1 \cdot 500^{*}$ & 2 & $1 \cdot 858$ & 7 & $1 \cdot 861$ & 2 \\
\hline $\mathbf{x}$ & 3.045 & 24 & $2 \cdot 158$ & 17 & 2.079 & 18 \\
\hline $\mathbf{Y}$ & $2 \cdot 000$ & 12 & & & $2 \cdot 122$ & 21 \\
\hline
\end{tabular}

Level of significance (two-tailed) ${ }^{*}, \mathrm{p}<0.005, \dagger, 0.005<\mathrm{p}<0.01$, $\ddagger, 0.01<p<0.025$. 
values, the level of significance for the $\chi^{2}$ test performed between the distribution of the $\mathrm{d}^{2}$ values for this particular chromosome pair and the reference distribution, and the rank value. Lowest rank values are given to the most centrally located chromosomes.

From this table it is clear that chromosome pair 6 in both controls is located significantly more peripherally in the metaphase plate, while chromosome pairs $13,15,21$, and 22 are significantly more central in the XY population. In contrast to these findings, chromosome pair 6 is located more centrally and the acrocentric chromosomes are located more peripherally in the XXY population than in both control populations. Moreover, a significantly central location of chromosome pair 1 and a distribution statistically different from the reference distribution of chromosome pair 17 are observed in the XXY population.

\section{$d^{2}$ comparison between the $X X Y$ population and the control populations}

Contrasting with the significant positive correlation coefficient between the $\overline{\mathrm{d}}^{2}$ values of both control populations $(r=0.6931$, significant at the $p=0.01$ level with $n-2=20 \mathrm{df}$ ), correlation coefficients between the $\overline{\mathrm{d}}^{2}$ values of the XXY population and the $\overline{\mathrm{d}}^{2}$ values of the $\mathrm{XX}$ population $(\mathrm{r}=\mathbf{0} \cdot 2370$, $\mathrm{df}=20$ ) or the $\overline{\mathrm{d}}^{2}$ values of the $\mathrm{XY}$ population $(r=0.4128, d f=21)$ are low and not significant. Since this study deals with a population of subjects with an abnormal complement of gonosomes, it might be interesting to have a closer look at the specific gonosomal $\overline{\mathrm{d}}^{2}$ values. We therefore performed $\chi^{2}$ tests between the distribution of the $\mathrm{d}^{2}$ values of the gonosomes in the XXY population and the distribution of the $\mathrm{d}^{2}$ values of the corresponding gonosomes in the control population. No significant differences were observed for the centromere-centre distances of the $\mathrm{X}$ or $\mathrm{Y}$ chromosomes between patient and control populations.

\section{$\triangle^{2}$ DISTANCES AND ANGLE VALUES BETWEEN HOMOLOGOUS AND NON-HOMOLOGOUS COMBINATIONS}

$\chi^{2}$ tests within the control populations and the patient populations

The comparison of the $\Delta^{2}$ distributions of each chromosome combination with the $\Delta^{2}$ reference distribution gives a list of chromosome combinations significantly different from the reference distribution. Similar data are obtained for the angle values. Biological significance cannot be assigned to all statistically significant combinations, but might be inferred for those which showed significant deviations
TABLE $2 \bar{\Delta}^{2}$ values and mean angle values for those chromosome distributions which were shown by $\chi^{2}$ tests to present a distribution of both $\Delta^{2}$ values and angle values significantly different from their corresponding reference distribution

\begin{tabular}{|c|c|c|c|c|}
\hline $\begin{array}{l}\text { Chromosome } \\
\text { distribution }\end{array}$ & $\begin{array}{l}\bar{\Delta}^{2} \\
\text { value }\end{array}$ & $p$ & $\begin{array}{l}\text { Mean } \\
\text { angle } \\
\text { value }\end{array}$ & $p$ \\
\hline \multicolumn{5}{|l|}{$X X$} \\
\hline $\begin{array}{l}13-21 \\
9-13 \\
\text { Reference } \\
\text { distribution } \\
4-7 \\
13-16\end{array}$ & $\begin{array}{l}3 \cdot 214 \\
3 \cdot 944 \\
4 \cdot 089 \\
4 \cdot 431 \\
4 \cdot 603\end{array}$ & $\begin{array}{l}p<0.005 \\
0.05>p>0.025 \\
0.025>p>0.01 \\
0.025>\text { p }>0.01\end{array}$ & $\begin{array}{r}79 \cdot 71 \\
86 \cdot 72 \\
\\
91 \cdot 56 \\
99 \cdot 85 \\
105 \cdot 89\end{array}$ & $\begin{array}{l}0.025>p>0.01 \\
0.05>p>0.025\end{array}$ \\
\hline \multicolumn{5}{|l|}{$X Y$} \\
\hline $\begin{array}{l}21-22 \\
13-15 \\
14-21 \\
13-18 \\
13-14 \\
\text { Reference } \\
\text { distribution } \\
3-8 \\
5-8 \\
3-4 \\
X-3\end{array}$ & $\begin{array}{l}2 \cdot 924 \\
3 \cdot 148 \\
3 \cdot 251 \\
3 \cdot 260 \\
3 \cdot 331 \\
4 \cdot 089 \\
4 \cdot 597 \\
4 \cdot 733 \\
4 \cdot 798 \\
5 \cdot 678\end{array}$ & $\begin{array}{l}\mathrm{p}<0.005 \\
\mathrm{p}<0.005 \\
\mathrm{p}<0.005 \\
0.025>\mathrm{p}>0.01 \\
\mathrm{p}<0.005\end{array}$ & $\begin{array}{l}87 \cdot 62 \\
83 \cdot 94 \\
82 \cdot 32 \\
83 \cdot 22 \\
83 \cdot 23 \\
91 \cdot 15 \\
97 \cdot 50 \\
94 \cdot 67 \\
95 \cdot 24 \\
91 \cdot 50\end{array}$ & $\begin{array}{l}0.025>p>0.01 \\
0.05>p>0.025 \\
p<0.005 \\
p<0.005 \\
p<0.005\end{array}$ \\
\hline \multicolumn{5}{|l|}{$X X Y$} \\
\hline $\begin{array}{l}21-21 \\
1-22 \\
13-14 \\
14-15 \\
1-16 \\
15-21 \\
\text { Reference } \\
\text { distribution } \\
3-4 \\
8-18 \\
11-13\end{array}$ & $\begin{array}{l}3 \cdot 520 \\
3 \cdot 593 \\
3 \cdot 670 \\
3 \cdot 690 \\
3 \cdot 700 \\
3 \cdot 808 \\
4 \cdot 087 \\
4 \cdot 129 \\
4 \cdot 339 \\
4 \cdot 499\end{array}$ & $\begin{array}{l}0.01>p>0.005 \\
0.025>p>0.01 \\
0.01>p>0.005 \\
0.05>p>0.025 \\
0.05>p>0.025 \\
p<0.005\end{array}$ & $\begin{array}{l}81 \cdot 96 \\
98 \cdot 27 \\
85 \cdot 77 \\
87 \cdot 49 \\
91 \cdot 32 \\
85 \cdot 44 \\
91 \cdot 34 \\
93 \cdot 57 \\
90 \cdot 30 \\
94 \cdot 97\end{array}$ & $\begin{array}{l}0.05>p>0.025 \\
0.05>p>0.025 \\
p<0.005 \\
0.025>p>0.01 \\
0.01>p>0.005 \\
0.05>p>0.025\end{array}$ \\
\hline
\end{tabular}

for both $\Delta^{2}$ values and angular values. We therefore listed (table 2), for each population studied, the chromosome combinations which proved to be significantly different from the reference distribution for both the centromere-centromere distances and the angle values: from left to right are the significant chromosome combinations, the mean $\Delta^{2}$ value of this particular chromosome combination, the level of significance for the $\chi^{2}$ test performed between the distribution of the $\Delta^{2}$ values for this particular chromosome combination and the corresponding reference distribution, the mean angle value, and the level of significance for the $\chi^{2}$ test performed between the distribution of the angle values for this particular chromosome combination and the corresponding reference distribution.

Attention will be paid more directly to the combinations which present a mean $\Delta^{2}$ value smaller than that in the reference distribution. The chromosomes involved are those which lie more closely to each other than expected in a random 
TABLE $3 \bar{\Delta}^{2}$ values in $X X Y, X X$, and $X Y$ populations for those gonosome-autosome combinations shown to present significantly different $\Delta^{2}$ distributions by $\chi^{2}$ tests comparing each $\Delta^{2}$ histogram in the $X X Y$ population with is corresponding histogram in the $X X$ and/or $X Y$ population

\begin{tabular}{|c|c|c|c|c|c|}
\hline $\begin{array}{l}\text { Chromosome } \\
\text { combination }\end{array}$ & $\bar{\Delta}^{2}$ value in $X X Y$ & $\bar{\triangle}^{2}$ value in $X X$ & $\begin{array}{l}\text { Level of significance } \\
\Delta^{2} X X Y \| \Delta^{2} X X\end{array}$ & $\bar{\triangle}^{2}$ value in $X Y$ & $\begin{array}{c}\text { Level of significance } \\
\Delta^{2} X X Y \| \bar{\Delta}^{2} X Y\end{array}$ \\
\hline $\begin{array}{r}3-X \\
5-X \\
6-X \\
7-X \\
11-X \\
12-X\end{array}$ & $\begin{array}{l}4 \cdot 160 \\
4 \cdot 049 \\
4 \cdot 074 \\
4 \cdot 325 \\
4 \cdot 503 \\
4 \cdot 098\end{array}$ & $\begin{array}{l}4 \cdot 927 \\
4 \cdot 720 \\
4 \cdot 490 \\
4 \cdot 095 \\
4 \cdot 739\end{array}$ & $\begin{array}{l}\mathbf{0 . 0 0 5}<\mathrm{p}<0.01 \\
\mathrm{p}<0.005 \\
\text { NS } \\
\text { NS } \\
\mathbf{0 . 0 1}<\mathrm{p}<\mathbf{0 . 0 2 5}\end{array}$ & $\begin{array}{l}5 \cdot 678 \\
5 \cdot 506 \\
5 \cdot 367 \\
5 \cdot 443\end{array}$ & $\begin{array}{l}0.005<\mathrm{p}<0.01 \\
0.025<\mathrm{p}<0.05 \\
\text { NS } \\
\text { NS }\end{array}$ \\
\hline $\begin{array}{r}6-Y \\
8-Y \\
11-Y \\
17-Y \\
22-Y\end{array}$ & $\begin{array}{l}4 \cdot 402 \\
4 \cdot 026 \\
4 \cdot 712 \\
4 \cdot 586 \\
4 \cdot 186\end{array}$ & & & $\begin{array}{l}4 \cdot 608 \\
4 \cdot 285 \\
4 \cdot 424 \\
4 \cdot 027 \\
3 \cdot 231\end{array}$ & $\begin{array}{l}\text { NS } \\
\text { NS } \\
\text { NS } \\
\text { NS } \\
0.01<p<0.05\end{array}$ \\
\hline
\end{tabular}

distribution. Not too much importance can be given to the number of significant associations, since in an organised structure this number is partly dependent on the number of metaphases examined.

As expected from previous work, ${ }^{8}$ acrocentric chromosomes are often involved in associations in both normal and XXY subjects. Associations involving $\mathrm{C}$ heterochromatin rich chromosomes are found more often in the XXY population (1-22, $1-16)$ than in the controls (13-16). There are some additional associations in the XXY population which are more difficult to explain $(3-4,8-18)$.

$\chi^{2}$ tests between the different populations

$\chi^{2}$ tests were performed between the distribution of the $\Delta^{2}$ values of the different populations to answer two questions.

(1) Do there exist some modifications of association between an autosome and a gonosome in patients with an abnormal gonosomal complement? Table 3 summarises the results obtained by comparing the XXY population with both control populations for those distributions which were significantly different from the reference distribution in either patient or control population. In the XXY population it seems that the two $X$ chromosomes lie significantly closer to chromosome pairs 3,5 , and 12 than in the $\mathrm{XX}$ population, and significantly closer to chromosome pairs 3 and 6 than in the XY population. However, since the mean $\Delta^{2}$ value of the reference distribution is about 4.087 one would consider them to be not more associated but rather less dissociated. The combination 22-Y for a similar reason is significantly dissociated as compared with the $\mathrm{XY}$ control population.

(2) Do there exist some modifications of the distribution of the gonosomes in patients with an abnormal gonosomal complement? $\chi^{2}$ ن tests were performed to compare the distri- 음 butions of $\Delta^{2}$ values for all gonosomal com- binations between the XXY and control Tr populations. Although no significant differences $\frac{D}{-}$ between patient and control populations could be established, on this criterion or by association tendency analysis, it was noticeable that the $\bar{\Delta}^{2} \vec{\bullet}$ distances between $X$ and $Y$ are smaller in the XXY $(4 \cdot 114)$ population than in the $X Y$ control population $(5 \cdot 329)$. The distance between the 0 two $\mathrm{X}$ chromosomes is unchanged in the $\mathrm{XXY}$ $(4 \cdot 103)$ population as compared to the $\mathrm{XX}$ o population $(4 \cdot 027)$.

\section{Discussion}

As mentioned earlier, age, ${ }^{12} 13$ culture conditions, ${ }^{12} 14$ 吾 mutagens, ${ }^{15-17}$ and viral infection ${ }^{18}$ all influence the distribution of human chromosomes. Populations examined, therefore, must be as homogeneous as $\dot{0}$ possible. We must first take into account a possible 3 . error owing to age variation since it was not possible to collect enough subjects of the same age. Recent $\frac{3}{3}$ studies (Hens et al, in preparation) comparing the $\mathrm{O}$ distributions of the $\mathrm{d}^{2}$ values for the different chromosome combinations in a population of 20- $\frac{7}{2}$ year-old normal women with the corresponding distributions of the $\mathrm{d}^{2}$ values in a population of $N$ 40-year-old women (correlation coefficient between $N$ the mean $\mathrm{d}^{2}$ values for the different chromosome $N$ combinations in the two populations $=0.855$ ) showed that ageing does not significantly modify the $\mathrm{d}^{2}$ distance parameter but induces some dissociations of acrocentrics.

A second parameter which has to be considered is the importance of intra- and interpersonal variation. The establishment of a significant difference between two populations depends on 
finding greater variation between two populations than between subjects within the populations. However, although detailed analysis is not possible if interpersonal variation is not taken into account, the relatively large number of subjects examined in both populations shows the major characteristic differences between the populations.

The most striking observation from our data is that the presence of an extra chromosome coincides with a disturbance of the theoretically stable centromere-centre distribution pattern of human chromosomes. These data might favour the hypothesis of Mikamo ${ }^{1}$ that spindle degeneration as a result of intrafollicular ageing may be a mechanism for non-disjunction in trisomies. Moreover, since centromere-centre distances might be related to replication time, ${ }^{5}$ the biological importance of these findings might be related to the modification of the duration of $\mathbf{S}$ phase and cell cycle in patients with abnormal karyotypes. ${ }^{19-22}$

Non-disjunction might also result from close associations between chromosomes, as shown in trisomy $21 . .^{2}$ Our position analysis method, however, does not clearly indicate such associations for sex chromosomes. Indeed, no $\mathrm{XX}$ association was observed in the XXY population. However, to analyse this parameter correctly, metaphases with labelled late replicating chromosome(s) would be more useful. An association between $X$ and $Y$ chromosomes might be supported by our findings since it was observed that the $\bar{\Delta}^{2}$ value of $X Y$ is lower in the XXY population than in the $X Y$ population. On the basis of these observations we therefore consider that no clear-cut evidence is given by the method of generalised distances for the induction of gonosomal trisomy XXY by association.

As far as associations between autosomes are concerned, one previous work $^{23}$ suggests that the presence of a supernumerary chromosome does not significantly modify the association between human acrocentric chromosomes. These results are almost confirmed by our generalised distances analysis of XXY karyotypes. However, it must be mentioned that the acrocentric chromosomes are located less centrally in the XXY population. Moreover, in the $\mathrm{XXY}$ karyotypes, the $\mathrm{C}$ heterochromatin rich chromosomes are more often associated than in the control populations.

Preliminary results collected by us separately on $21 \mathrm{XXX}, 16 \mathrm{XXYY}$, and $27 \mathrm{XYY}$ karyotypes confirm the results described here. The centromerecentre disturbance seems even more important. No significant $\mathrm{XX}$ or $\mathrm{YY}$ associations were observed in patients with a supplementary $\mathrm{X}$ or $\mathrm{Y}$ chromosome, but a decrease of acrocentric associa- tions was observed with a parallel increase of associations between $\mathrm{C}$ heterochromatin rich chromosomes. However, some particular abnormal heteromorphism of acrocentrics or $\mathrm{C}$ heterochromatin regions or both may play an important role in the modified centromere-centromere pattern of the chromosome distributions of the patients. Analysis of patients with an abnormal gonosomal complement by $\mathrm{C}$ banding and NOR banding would therefore be useful to clarify the possible role of $\mathrm{C}$ heterochromatin in the induction of gonosomal trisomies.

Although the study of chromosome organisation in Klinefelter's syndrome is interesting in itself, one may question how relevant this study can be to the origin of non-disjunction. Indeed, since nondisjunction occurs during meiosis it is evident that the analysis of the arrangement of the chromosomes should preferably be done in the parents of cases. However, for acrocentric chromosomes, different authors have shown not only the inheritance of $\mathrm{Ag}$ stainability of nucleolus organiser regions, ${ }^{24-26}$ but also the inheritance of acrocentric association patterns. ${ }^{27} 28$ We therefore suggest that nondisjunction should be analysed by comparative analysis of chromosome arrangement in parents of numerically abnormal subjects and in their progeny.

\section{References}

1 Mikamo K. Intrafollicular overripeness and teratologic development. Cytogenetics 1977; 7:212-33.

2 Cooke P, Curtis DJ. General and specific patterns of acrocentric association in parents of mongol children. Humangenetik 1974;23:279-87.

3 Henderson AS, Warburton D, Atwood KC. Ribosomal connectives between human acrocentric chromosomes. Nature 1973;243:95-7.

4 Miller DA, Tantravahi R, Dev VG, Miller OJ. Frequency of satellite association of human chromosomes is correlated with amount of Ag-staining of the nucleolus organizing region. Am J Hum Genet 1977;29:490-502.

5 Kirsch-Volders M, Hens L, Susanne C, GalperinLemaître H. Stability of centromere-centre distances in normal human metaphases. Cytogenet Cell Genet 1977; 18:61-74.

6 Defrise-Gussenhoven E. Generalized distances in genetic studies. Acta Genet (Basel) 1967;17:275-88.

7 Galperin-Lemaître H, Hens L, Kirsch-Volders M, Susanne C. Non-random association of trypsin-banded human acrocentric chromosomes. Hum Genet 1977;35: 261-8.

${ }^{8}$ Hens L, Kirsch-Volders M, Susanne C, GalperinLemaître H. Relative position in trypsin banded homologous chromosomes in human ( + ) metaphase figures. Humangenetik 1975;28:303-11.

9 Moorhead PS, Nowell PC, Mellman WJ, Battips DM, Hungerford DA. Chromosome preparations of leucocytes cultured from peripheral blood. Exp Cell Res 1960;20: 613-6. 
10 Galperin H. Relative positions of homologous chromosomes or groups in male and female metaphase figures. Humangenetik 1969;7:265-74.

11 Barton D, David FN, Merrington M. The analysis of chromosome patterns in the normal cell. Ann Hum Genet $1965 ; 29: 139-46$.

12 Mattevi MS, Salzano FM. Effect of sex, age and cultivation time on number of satellites and acrocentric associations in man. Humangenetik 1975;29:265-70.

13 Prokofieva-Belgovskaya AA, Gindilis VM, Grindberg $\mathrm{KN}$, et al. Association of acrocentric chromosomes in relation to cell type and age of individuals. Exp Cell Res $1968 ; 49: 612-25$.

14 Hoehn $\mathrm{H}$, Nagel $\mathrm{W}$, Krone $\mathrm{W}$. In vitro alteration of association pattern of human acrocentric chromosomes. Humangenetik $1971 ; 11$ :146-54.

15 Verschaeve L, Driessen M, Kirsch-Volders M, Hens L, Susanne C. Chromosome distribution studies in phenylmercury-acetate exposed subjects and in age related controls. Mutat Res 1978;57:335-47.

16 Verschaeve L, Driessen M, Kirsch-Volders M, Hens L, Susanne C. Chromosome distribution studies after inorganic lead exposure. Hum Genet 1979;49:147-58.

17 Kirsch-Volders M, Poma K, Verschaeve L, Hens L, Van Elegem P, Susanne C. Comparison of cytogenetic effects after occupational exposure to $\mathrm{X}$-rays with those after foetal pelvimetric exposure. International Symposium on Late Biological Effects of I Radiation. Vienna: IAEA SM-224/303, vol 1. 1978:493-505.

18 Heneen WK. Silver staining and nucleolar patterns in human heteroploid and measles-carrier cells. Hereditas $1978 ; 88: 213-27$.

19 Kaback M, Bernstein LH. Biological studies of trisomic cells growing in vitro. Ann NY Acad Sci 1970;171:526-36.
20 Paton GR, Silver MF, Allison AC. Comparison of celద cycle time in normal and trisomic cells. Humangenetik: 1974;23:173-82.

21 Schneider EL, Epstein CJ. Replication rate and lifespan of cultured fibroblasts in Down's syndrome. Proc So Exp Biol Med 1972;141:1092-4.

${ }^{22}$ Dutrillaux B, Fosse AM. Utilisation du BrDu dans̄ l'etude du cycle cellulaire de sujets normaux et anormaux $\overrightarrow{\mathbb{D}}$ Ann Genet (Paris) 1976;19:95-102.

23 Higurashi M, Conen PE. Comparison of chromosomap behaviour in cultured lymphocytes and fibroblasts from patients with chromosomal disorders and controls: Cytogenetics $1971 ; 10: 273-5$.

24 Mikelsaar AV, Schwarzacher HG, Schnedl $w \vec{\omega}$ Wagenbichler P. Inheritance of Ag-stainability oD nucleolus organizer regions. Hum Genet 1977;38:183-8.

${ }_{25}$ Markovic VD, Worton RG, Berg JM. Evidence for the inheritance of silver-stained nucleolus organizer regions $\overrightarrow{-}$ Hum Genet 1978;41:181-7.

${ }^{26}$ Henderson LM, Bruère AN. Association of nucleolus $\vec{g}$ organizer chromosomes in domestic sheep. Cytogenex Cell Genet 1977;19:326-34.

27 Phillips RB. Inheritance of acrocentric association? patterns. Humangenetik 1975;29:309-18.

28 Mattei JF, Mattei MG, Ayme S, Gouvernet J, Giraud $F_{\mathbb{D}}^{T}$ Inheritance of acrocentric association patterns. In $\mathrm{D}$ Szabo G, Papp Z, eds. Proceedings of the Symposium or Medical Genetics, Debrecen. Amsterdam: Excerptân Medica, 1977:107-15.

Requests for reprints to $\operatorname{Dr} M$ Kirsch-Volders, Laboratorium voor Antropogenetika, Vrije Universiteit Brussel, Pleinlaan 2 F4, 1050 Brussels

Belgium. 